\title{
Walter Benjamin e a busca do presente no século XIX
}

Melissa Boëchat

UFMG

Resumo: O presente artigo faz um recorrido sobre os dois exposés das Passagens de Walter Benjamin, analisando a relação feita por ele entre os elementos urbanos da Paris no século XIX e os personagens históricos a eles associados, no intuito de verificar a questão da modernidade e as relações humanas no século XIX.

Palavras-chave: Walter Benjamin, Passagens, Modernidade.

O século XIX pode ser considerado um século de conflitos entre o novo e o antigo, entre o espaço urbano e o espaço campesino, entre a nostalgia do passado e a ansiedade do futuro - um "entre-século", se assim podemos determinar -, uma época cuja característica mais marcante é a transformação, deixando de ser aquilo que fora, mas ainda sem se tornar o que viria a ser. O surgimento das metrópoles, e mais especificamente a consolidação de Paris como a grande capital européia, criou um novo tipo de homem, dividido entre o trabalho incessante, causador do ritmo frenético do novo modo de produção que então surgia, e seu intérieur, instância onírica e nostálgica que o atraía a um universo irrecuperável de tranqüilidade e reflexão.

“(...) as cidades, em vez de serem cuidadas qual obras, são tratadas como produtos e, deixando de se constituírem em fins, degradam-se em meios para a produção e a circulação de bens e serviços". ${ }^{1}$ Assim é a imagem que se pode fazer da Paris do século XIX. A aglomeração de trabalhadores que migram do modo de produção feudal para o industrial recheia a cidade e torna-se um excelente campo de observação para mentes como as de Walter Benjamin e Charles Baudelaire, observadores argutos do mundo que então se desvela ante seus olhos.

Diferenciando-se de Baudelaire por apresentar-se menos melancólico, Benjamin, com o recurso que possuía antes do surgimento dos panoramas, representa e registra esse universo insólito através de Das Passagen-Werk, obra inacabada - como a própria Paris sobre a qual discorre, ainda por construir-se e como o próprio século em questão composta por fragmentos que tentam, em sua relação intrínseca, propor uma "filosofia material da história do século XIX".2 
As passagens, "aquários humanos" revestidos e estruturados pelo vidro e pelo ferro - elementos que a arquitetura moderna começa na época a inserir na construção das cidades -, são espaço de indagações e de vivência dos primórdios da modernidade. Os fenômenos urbanos, tão palpavelmente materiais, se confundem com a névoa densa dos sonhos, fusão que, segundo Benjamin, se aproximaria do ideal para a realização de uma análise histórica e social do que o século XIX representou no percurso da humanidade.

A obra das Passagens - ou simplesmente Passagens, como foi traduzida para o português - reúne dois textos conclusos e vários fragmentos, comentados ou não por Benjamin, que comporiam a totalidade de seu trabalho. É justamente sobre os dois primeiros textos terminados - "Paris, a capital do século XIX", com o exposé de 1935 e o de 1939 - que versa este breve estudo. Embora praticamente iguais, os dois textos apresentam algumas diferenças importantes para a compreensão do trabalho de Benjamin.

O primeiro exposé, escrito em maio de 1935, se divide em seis partes que se configuram como instâncias da modernidade que aparentam anunciar o novo universo sobre o qual Walter Benjamin discorre, a saber: as passagens, os panoramas, as exposições universais, o intérieur, as ruas de Paris e as barricadas. Cada uma dessas partes relaciona um aspecto físico de Paris a uma personalidade importante que a ele se associa. Seguindo o mesmo esquema, entretanto com uma parte a menos, o exposé de 1939 - que fora solicitado a Benjamin por Horkheimer na tentativa de obter auxílio financeiro para o Instituto de Pesquisa Social -, está composto por cinco partes, nas quais se pode perceber a evolução do pensamento benjaminiano sobre os mesmos temas, durante os quatro anos que se passaram entre os dois textos.

Benjamin, sobre as passagens - que relaciona a Fourier - faz um relato sobre tais estruturas comerciais, surgidas em 1822. Cito Benjamin: “As passagens são o centro das mercadorias de luxo"; 3 sua relação com o passado, arquitetonicamente forjada na Grécia Antiga, revela a relação do século XIX com a valorização do passado, que não possui a referência do velho, mas sim o ideal de valorização do antigo. As passagens são um espaço de isolamento do homem de qualquer contato com o mundo externo natural. São cobertas, imunes ao sol e à chuva, atemporais. Aparecem, em oposição harmoniosa ao culto do antigo, forjadas com novos elementos arquitetônicos, como o ferro e o vidro. O 
ferro, elemento de estruturas comerciais e transitórias como pavilhões e estações de trem, surge como elemento relacionado ao belo; já o vidro envolve o centro comercial em uma atmosfera onírica, materializando nas passagens a ambigüidade característica do século XIX.

A associação da figura de Fourier e dos falanstérios aporta um duplo sentido para as passagens: o comercial e o residencial, um falanstério constituído por passagens, um universo que ultrapassa o real / material para reforçar a utopia de uma sociedade em que cada indivíduo trabalha no que quer e na qual os bens comuns são compartilhados. A inclusão de Fourier nesse trecho parece um tanto obscura e incompleta, entretanto, no exposé de 1939 tal inserção se justifica mais claramente, uma vez que Benjamin acrescenta outras considerações sobre o socialista utópico francês, que terminou por prever o encontro dos cidadãos em espaços comuns, cenários ideais para o flâneur.

Os panoramas não são mencionados no exposé de 1939, ficando sua aparição e comentários limitados ao primeiro texto de 1935. Sobre eles, justificadamente associados à figura de seu criador, Daguerre, Benjamin delineia a emancipação da arte da arquitetura, assim como da pintura dos panoramas. Os daguerreótipos abrem o caminho da arte à fotografia e ao cinema, e seu surgimento não se limita apenas à representação imagética, expandindo-se ao universo da própria literatura, dando origem à chamada literatura panoramática. A modernidade se desvela através do uso da técnica na arte, a cidade se transforma em paisagem, a fantasmagoria aparece na mistura até então insólita entre a arte e a técnica.

$\mathrm{Na}$ seguinte imagem de um panorama de Daguerre, pode-se perceber que o espaço físico predomina, a metrópole se conforma como ambiente, pano de fundo, palco das atividades sociais do século XIX. Entretanto, a técnica não permite o registro de praticamente nenhum ser humano, uma vez que a imagem deveria permanecer estática por certo período de tempo para que fosse registrada. A velocidade da vida "moderna" permitiu o registro / rastro de apenas uma figura humana, no canto inferior esquerdo da imagem, que provavelmente (e estranhamente) permaneceu parada tempo suficiente para ser captada pela imagem de Daguerre. 


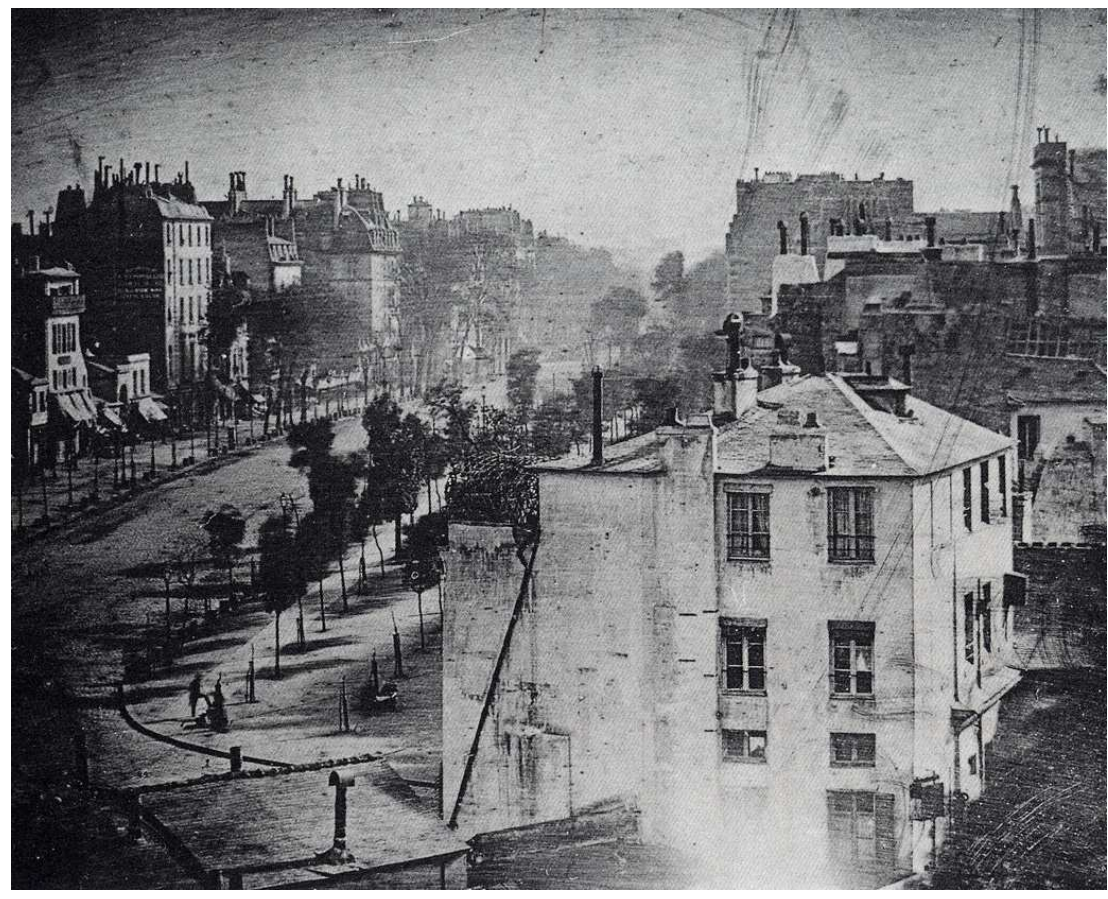

Figura 1: Panorama de Daguerre: Boulevard parisien

A polêmica existente sobre a possibilidade de diálogo entre estes dois universos - arte e técnica - tem aqui um de seus primeiros momentos, delineados por Benjamin principalmente no que se refere à relação entre a fotografia e a pintura. A inserção da fotografia nas Exposições Universais (especificamente na de 1855, que ofereceu uma mostra especial sobre o tema) e sua primazia nos meios de comunicação enquanto informação ampliam sua presença na esfera mercantil, fazendo com que seja necessário buscar novos objetos e novas técnicas. A própria cidade adquire um novo papel, passando de sua limitada e infernal função de espaço físico de relações sociais e comerciais, a fazer parte da representação fotográfica enquanto elemento artístico.

As exposições universais, recém mencionadas, surgem como o terceiro tema do exposé de 1935, e o segundo de 1939. É nelas que a mercadoria assume seu máximo posto de fetiche, sendo cultuada através da moda. Os objetos não valem por seu uso, mas sim enquanto objetos em si mesmos, por seu valor de troca. Esses eventos trazem as camadas operárias em primeiríssimo plano, no papel de clientes; são predecessores da indústria do entretenimento, um acontecimento de distração das massas operárias, aproximando-as, ainda que em um plano surreal, do luxo e da moda.

Sobre o mesmo tema, no exposé de 1939, se percebe em Benjamin um olhar mais centrado na classe proletária e seu olhar sobre o espetáculo das exposições - 
poder-se-ia ousar, inclusive, em considerá-lo um olhar mais interno. A participação das massas nas exposições universais assume uma "atitude claramente reacionária", o aproveitamento dos prazeres fugidios que a elas propiciam contrasta com o ritmo desumanizador do trabalho industrial. No exposé de 1939, Benjamin insere, ainda, um comentário sobre a moda, que se faz agora responsável por unir o corpo humano ao corpo inorgânico da cidade, fundindo elementos naturais aos objetos que compõem o cotidiano das mulheres parisienses.

Através destes elementos "exteriores", somados às barricadas e às ruas de Paris, que veremos mais adiante, Benjamin traça aos poucos o plano da capital francesa - e até mesmo européia - do século XIX, uma cidade que vive acelerada em relação ao seu próprio tempo, obrigando seus sujeitos a acompanhá-la em seu ritmo frenético, o que termina por levá-los a uma anulação de si mesmos enquanto indivíduos. O resgate dessa instância forçosamente apagada do homem parisiense surge nas considerações sobre Luis Filipe ou o intérieur. Aqui aparece claramente a oposição entre as duas esferas sociais - a esfera pública, representada pelos escritórios, pelas indústrias, pelas lojas, pelos locais de trabalho em geral, e a esfera privada, intérieur, campo das ilusões que devem servir de sustentáculo para a realidade.

O espaço interno, a casa, passa a ser a "expressão da personalidade", a arquitetura e a decoração passam a fazer parte do circuito artístico, uma vez que o intérieur, para Benjamin, é primeiramente o refúgio da arte, passando depois a asilo da arte (diferentes conceituações por ele utilizadas nos exposés de 1935 e 1939, respectivamente). As obras de arte passam a valer como peças de colecionador, objetos que não apresentam valor de uso, mas sim afetivo.

Segundo Benjamin,

O colecionador se compraz em suscitar um mundo não apenas longínquo e extinto, mas, ao mesmo tempo melhor, um mundo em que o homem, na realidade, é tão pouco provido daquilo de que necessita como no mundo real, mas em que as coisas estão liberadas da servidão de serem úteis. ${ }^{4}$

Benjamin cita o arquiteto belga Van de Velde, ressaltando sua posição funcionalista frente à construção, que na realidade representa a expressão de seu morador. A casa passa a ser a casca do homem parisiense do século XIX, e através dela, 
um bom fisionomista pode apreender o interior de seu proprietário, pois ele invariavelmente deixa rastros de si no intérieur. Esses rastros, como são expostos no exposé de 1939, terminam por ser não apenas uma indenização, uma compensação da ausência e do distanciamento do homem de si mesmo na esfera pública; acabam por servir também como sementes do romance policial que surge na época, originando-se justamente na busca e na recuperação desses vestígios.

É também em seu segundo texto sobre o intérieur que Benjamin fala sobre o fim dessa instância; a arquitetura parte da eliminação da funcionalidade para uma vertente do estilo, juntamente com o Jungendstil. A verdadeira faceta do cidadão reside - e aqui se percebe um retorno aos princípios de Fourier - nos escritórios e locais de trabalho. O intérieur é uma fuga, uma ilusão, um mundo fictício.

O homem do século XIX começa a encontrar novas formas de relacionar-se no espaço da metrópole. O intérieur, as exposições universais e até mesmo o espaço dos daguerreótipos são novas instâncias que a modernidade lhe oferece para que ele possa definir-se como ser social, não apenas como uma peça a mais da engrenagem acelerada da modernidade. No interior de sua casa deixa traços de sua presença, imprime sua existência e sua identidade através das mercadorias que adquire ou até mesmo fisicamente, nos novos elementos decorativos como o veludo.

Saindo do intérieur Benjamin nos abre as portas das ruas de Paris, espaço que respira, em cada canto, a presença de Baudelaire. Em um movimento contrastivo de aproximação e distanciamento, o poeta fala de seu universo a partir de um olhar exterior. Baudelaire escreve de um panóptico, de onde não vigia, mas observa todo e qualquer movimento que a cidade realiza. É a figura do flâneur, que acaba fazendo parte do mercado enquanto observador e engrenagem. O flâneur não pertence à cidade, se sente em casa apenas em meio à multidão, e observa o indivíduo que nada tem de individual, que se repete, que é sempre o mesmo. Reaparece em todo e qualquer rosto, repete os mesmos gestos, segue a mesma moda, como podemos observar em um dos versos do poema "Les sept vieillards", das Flores do Mal:

A quel complot infâme étais-je donc en butte, Ou quel méchant hasard ainsi m'humiliait?

Car je comptai sept fois, de minute en minute, Ce sinistre vieillard qui se multipliait! ${ }^{5}$ 
Baudelaire traz em sua obra o tom fúnebre da "morte da arte", ao entregar-se ao mercado. A morte leva ao novo, que é um aspecto que se converte em contraponto entre o valor das coisas e o valor da novidade para o poeta. O imprevisto se transforma em uma qualidade inalienável do belo: a novidade trazida pela moda. Entretanto, tal novidade também se repete, pois outra vez a moda surge enquanto repetição da aparência. As ruas de Paris se desenham como cenário desse triste teatro em que a arte deve lutar para proteger-se do desenvolvimento da técnica; Paris já não é uma capital geográfica, mas sim temporal, é a capital do século XIX.

É ainda nas ruas de Paris que se estabelecem as barricadas, último elemento abordado por Benjamin em seus exposés. Haussmann foi o responsável pela reestruturação da cidade, com o duplo objetivo de impedir a construção das barricadas e dar à cidade um aspecto mais nobre. A história econômica da especulação imobiliária divide a cidade em duas, um centro em que a moda e as figuras burguesas modernas confluem e uma periferia habitada por aqueles que não têm condições de pagar os elevados aluguéis da época. Surge então o aspecto desumano da grande cidade, que em seu projeto de embelezamento estratégico termina por, cada vez mais, afastar a classe proletária dos bairros burgueses.

Os conflitos que se expõem pelas ruas da metrópole são também conflitos internos. As lutas por melhores salários e por melhores condições de trabalho podem ser lidas como representações da própria luta interna que se vive no XIX. A insatisfação do cidadão europeu, sobre a qual muitas vezes ele próprio não chega a pensar por falta de tempo, explode no exterior. Em que tempo vivia o parisiense? Buscando o passado através de padrões de representação do belo e do artístico, como uma referência a que se agarrar na turbulência da cidade, ou vivendo a expectativa de uma época de luxo e conforto, na qual a modernidade, através da técnica, imprimiria seus padrões de felicidade, beleza e abastança? Talvez os dois, pois a transitoriedade que marca o século XIX se percebe nas relações humanas da época. A efemeridade da moda provocava constantes mudanças nos padrões e no gosto da sociedade, a arquitetura e o design oscilavam entre novas formas e novos elementos, acabando por forjar um padrão desconexo de mistura de estilos, efeitos e elementos. O próprio homem não se decide se sua identidade está plasmada na figura que representa na esfera social, em seu trabalho 
ou em seu círculo de relações, ou se o que ele intrinsecamente deseja e tem para si como ideal de ser humano em seu intérieur é o que o define como indivíduo.

A dualidade entre o real e o imaginário é nota evidente na modernidade. Parece não haver espaço para meios termos na metrópole. O cidadão urbano parece não se dar conta de que, por mais que se busque como indivíduo, há milhões iguais a ele, cidadãos inseridos em uma máquina produtiva que impõe seu ritmo a qualquer preço. Passado e futuro são instâncias que se tocam, impedindo a existência de um tempo em que se possa aproveitar a brevidade da vida e os frutos do trabalho excessivo. A própria arte oscila entre antigos padrões e novas funcionalidades. Indubitavelmente, é um tempo de mudanças que, indiferentes a qualificações ou críticas, ocorrem sem a participação consciente de seus agentes. A modernidade, enfim, parece descer sem freios e em alta velocidade a ladeira da história.

Por fim, Benjamin demonstra sua preocupação em tratar, como na revolução copernicana, o passado fundamentado na atualidade e a noção da história como continuum. Para ele,

O século não soube responder às novas virtualidades técnicas com uma nova ordem social. É por isso que a última palavra coube às mediações enganosas do antigo e do novo, que estão no coração de suas fantasmagorias. O mundo dominado por essas fantasmagorias é - para usarmos a expressão de Baudelaire - a modernidade. $^{6}$

Sérgio Paulo Rouanet, em seu artigo intitulado "História material em Walter Benjamin 'Trabalho das Passagens"” (1998), tenta responder à seguinte questão, que foi tema de um seminário sobre a cidade: é a cidade que habita os homens ou são eles que moram nela? Ele aponta como uma possível resposta de Benjamin: "o homem habita uma cidade real e é habitado por uma cidade de sonho", dicotomia que, na realidade, resume todo o trajeto percorrido por Walter Benjamin em "Paris, capital do século XIX". 7

Benjamin demonstra, por fim, que a modernidade se configura em um espaço de novidades - novidades que se sobrepõem umas às outras, em constante diálogo com o passado, novidades que se constroem a partir do passado. O cidadão parisiense do século XIX parece dirigir seu olhar simultaneamente a duas direções: ao que ficou para trás, em um universo de sonho que ele busca recuperar em seu interior, e ao que está por 
vir, real e infernal, acelerado e devorador, um futuro em que o exterior comanda suas ações e seu próprio ritmo. Nesse contraste entre duas temporalidades distintas, entre duas instâncias antagônicas, o homem do século XIX é o reflexo de sua época: um ser perdido no tempo e no espaço, nostálgico e melancólico como Baudelaire, contraditoriamente em busca de seu próprio presente, sem perceber que ele lhe é, e será sempre, inapreensível.

Resumen: Este artículo recorre los dos exposés de la obra Passagens de Walter Benjamin, analizando la relación por él establecida entre los elementos urbanos de París en el siglo XIX y los personajes históricos a ellos asociados, buscando verificar la cuestión de la modernidad y las relaciones humanas en el siglo XIX.

Palabras clave: Walter Benjamín, Passagens, Modernidad.

\section{Referências bibliográficas}

AZEVEDO, Ricardo Marques de. Uma Idéia de Metrópole no Século XIX. Revista Brasileira de História. [online]. 1998, vol. 18, no. 35 [citado 2008-05-04], pp. 165-183.

Disponível em: <http://www.scielo.br/scielo.php?script=sci_arttext\&pid=S010201881998000100007\& lng=pt\&nrm=iso>. ISSN 0102-0188. doi: 10.1590/S010201881998000100007. Acesso em: 08 maio 2008.

BAUDELAIRE, Charles. Les fleurs $d u$ mal. Edição digital. Disponível em http://www.ac-strasbourg.fr/pedago/lettres/fleurs/. Acesso em: 08 maio 2008.

BENJAMIN, Walter. Passagens. Belo Horizonte: Ed. UFMG, 2006. 1111p.

ROUANET, Sérgio Paulo. É a cidade que habita os homens ou são eles que moram nela? História material em Walter Benjamin "Trabalho das Passagens". Disponível em http://www.usp.br/revistausp/15/sergiop.php. Acesso em: 16 abr. 2008.

TIEDEMANN, Rolf. Prefácio. In BENJAMIN, Walter. Passagens. Belo Horizonte: Ed. UFMG, 2006, p. 13-33.

\section{Índice de imagens:}


Figura 1: Panorama de Daguerre - Boulevard parisien. Disponível em: http://www.yourshot.eu/blog/2_Daguerre_Boulevard\%20du\%20Temple_1838\%201839 .jpg > Acesso em: 07 out. 2008.

\section{Notas}

${ }^{1}$ LEFEVBRE apud AZEVEDO. Uma Idéia de Metrópole no Século XIX.

${ }^{2}$ TIEDEMANN. Prefácio, p. 13.

${ }^{3}$ BENJAMIN. Passagens, p. 40.

${ }^{4}$ BENJAMIN. Passagens, p. 59.

${ }^{5}$ BAUDELAIRE. Les sept vieillards.

${ }^{6}$ BENJAMIN. Passagens, p. 67.

${ }^{7}$ ROUANET. É a cidade que habita os homens ou são eles que moram nela? História material em Walter Benjamin "Trabalho das Passagens". 